\title{
Rare earth barium cobaltites: potential candidates for low-temperature oxygen separation
}

\author{
Aswathy M. Narayanan ${ }^{1} \cdot$ Arun M. Umarji ${ }^{1}$ (1)
}

Received: 2 January 2020 / Accepted: 8 February 2020 / Published online: 19 February 2020

(c) Springer Nature Switzerland AG 2020

\begin{abstract}
Oxygen storage materials with low operating temperatures have gained attraction in oxygen separation and enrichment applications. Herein, $\mathrm{YBaCO}_{2} \mathrm{O}_{6-x}, \mathrm{Dy}_{0.5} \mathrm{Y}_{0.5} \mathrm{BaCO}_{2} \mathrm{O}_{6-x}$ and $\mathrm{DyBaCO} \mathrm{O}_{6-x}$ are explored for low-temperature oxygen enrichment. These oxides were synthesized through solid-state reaction and the oxygen separation properties at various temperatures were studied using a home-built volumetric setup. The oxygen intake temperatures of the sample were found to vary depending upon the rare-earth cation size. The lowest absorption temperature of $523 \mathrm{~K}$ was observed for DyBaCo${ }_{2} \mathrm{O}_{6-x}$. Interestingly, $\mathrm{DyBaCO}_{2} \mathrm{O}_{6-x}$ had the largest saddle point radii through which oxide ion migration occurs. The effect of the synthesis method and microstructure on the oxygen holding capacity of $\mathrm{DyBaCO}_{2} \mathrm{O}_{6-x}$ has also been analyzed. For this, $\mathrm{DyBaCO} \mathrm{O}_{6-x}$ was synthesized through a combination of solution combustion synthesis followed by calcination and sintering at different temperatures. The particle size was found to have a profound effect on the oxygen intake of $\mathrm{DyBaCO}_{2} \mathrm{O}_{6-x}$.
\end{abstract}

Keywords Ceramics · Metal oxides · Defects · Oxide ion conduction · Oxygen storage materials · Rare earth barium cobaltite

\section{Introduction}

Transition metal oxides are utilized for wide variety of applications like catalysis, solid oxide fuel cell research, gas sensing and ion transport membranes due to the presence of metals in variable oxidation states [1-4]. Certain nonstoichiometric transition metal oxides can reversibly incorporate or release oxygen from their lattice by changing the ambient conditions $[5,6]$. A change in oxygen partial pressure or temperature of the surrounding can influence the oxygen content in their lattice. Thus, switching of ambient partial pressure of oxygen from low to high can incorporate oxygen selectively into the lattice and vice versa, achieving an efficient separation of oxygen from air [7].
Materials with this property are broadly known as oxygen storage materials [8].

A number of new oxygen storage materials have been discovered in recent years [6,9-20]. The oxygen intake/ release in these non-stoichiometric oxygen storage oxides takes place through the following steps [21], (1) oxygen molecules are diffused to the surface, (2) dissociative adsorption through electron transfer, (3) diffusion of the oxide ions from surface to the lattice through an activated hopping mechanism. The diffusion of oxide ions through the material depends on the ease with which ions can move freely inside the lattice. This in turn depends on the activation energy of ionic conduction and the volume of free space available for the oxide ions to move. Availability of larger free space to move and lower activation energy

Electronic supplementary material The online version of this article (https://doi.org/10.1007/s42452-020-2218-1) contains supplementary material, which is available to authorized users.

Arun M. Umarji, umarji@iisc.ac.in | ${ }^{1}$ Materials Research Centre, Indian Institute of Science, Bengaluru, Karnataka 560012, India. 
are preferred for ionic movement. Activation energy of ionic diffusion depends on the bonding in the lattice, whereas the free volume available to move depends purely on geometric factors of the lattice. According to F. Sammells and co-workers [22], the degree of openness or "free volume" $\left(V_{f}\right)$ of the lattice can be taken as the difference between the unit cell volume and total volume of the constituent atoms (Eq. 1). The migration of oxide ion occurs via a vacancy mechanism, and most readily along the $\langle 110\rangle$ edges of the $\mathrm{BO}_{6}$ octahedra. Ionic migration occurs through a saddle point formed by two $A$ and one $B$ site cations (Fig. 1) and the radius of which (critical radius, $r_{c}$ ) can be calculated from the radius of the $A$ and $B$ ions and the perovskite lattice parameter $\left(a_{p}\right)$ as per Eq. 2 [22].

Lattice free volume $\left(V_{f}\right)=V_{\text {unit cell }}-V_{\text {constituents }}$

Critical radius $\left(r_{c}\right)=\frac{r_{B}^{2}-r_{A}^{2}+\frac{3}{4} a_{p}^{2}-\sqrt{2} a_{p} r_{B}}{2 r_{A}+\sqrt{2} a_{p}-2 r_{B}}$

Manipulating these geometrical factors by substitution can result in changes in the oxygen intake/release temperatures. Oxygen storage materials operating at lower temperatures can utilize low temperature waste heat for oxygen separation. This in turn brings down the cost of oxygen production. Among the different perovskite and double perovskite oxides studied, A-site ordered double perovskites $\left[(\mathrm{RE}) \mathrm{BaB}_{2} \mathrm{O}_{6-x}\right]$ have been shown to have low oxidation temperatures, 373-573 K $[16,17,20]$. Of the $\mathrm{B}$-site cations $\mathrm{Mn}, \mathrm{Co}$ or $\mathrm{Fe}$, the manganese based ones being the most studied system because of the widest variation in oxygen content $[16,17,19,20]$. The range of non-stoichiometry in these materials varies between $0<$ $x<1$, depending upon the rare earth cation [2] and synthesis conditions [23,24]. The crystal structure is similar to

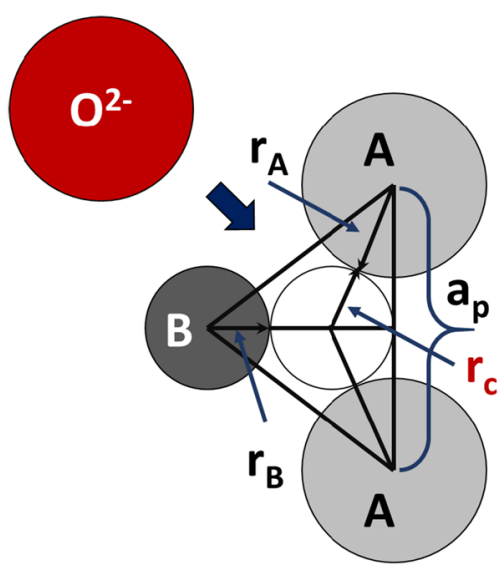

Fig. 1 Saddle point geometry and critical radius (adapted from reference [22]) perovskite while the difference being ordering of $\mathrm{Ba}$ and rare earth cation in alternating planes as stoichiometric $\mathrm{BaO}$ and non-stoichiometric (RE) $\mathrm{O}_{x}$ respectively. When it is reduced/oxidized, the oxygen atoms in the rare earth cation plane are preferentially removed/incorporated without collapsing the overall structure (Fig. 2). This is because the smaller rare earth cations prefer a lower oxygen coordination compared to larger Ba cations. These preferential vacancy channels give an enhanced oxide ion transport in these materials making them applicable in solid oxide fuel cells [2] and oxygen transport membranes [25].

As mentioned earlier, manganese based rare earth barium oxides have been studied extensively in the literature for oxygen storage applications $[17,19,20]$. Only limited studies on cobalt based rare earth barium oxides are available in the literature, which are inclined towards high temperature $(>973 \mathrm{~K})$ membrane separation $[25,26]$ or cathodes for solid oxide fuel cells [2]. Lekse et al. [16] reported a comparative study of the oxygen storage properties of $\mathrm{LnBaCO}_{2} \mathrm{O}_{6-x}$ and $\mathrm{LnBaFe}_{2} \mathrm{O}_{6-x}(\mathrm{Ln}=\mathrm{La}, \mathrm{Y})$ at $673 \mathrm{~K}$. They performed oxygenation/reduction in air/ $\mathrm{N}_{2}$ as well as in air/4\% $\mathrm{H}_{2}$-Ar. A higher amount of oxygen ions get reversibly incorporated upon reduction with $4 \% \mathrm{H}_{2}$-Ar reduction treatment. Thus, cobalt based double perovskites show reversible oxygen intake/release at intermediate temperatures similar to manganese double perovskites.

Herein, the three rare earth barium cobaltite double perovskite oxides, $\mathrm{YBaCo}_{2} \mathrm{O}_{6-x}, \mathrm{DyBaCO}_{2} \mathrm{O}_{6-x}$ and $\mathrm{Dy}_{0.5} \mathrm{Y}_{0.5} \mathrm{BaCO}_{2} \mathrm{O}_{6-x}$ have been explored for oxygen storage applications. The reason behind the selection of these oxides is three fold. First, the oxygen non-stoichiometry in ( $\mathrm{RE}) \mathrm{BaCO}_{2} \mathrm{O}_{6-x}$ is dependent upon the rare earth cation size, thus the effect of cation size on the oxygen intake/ release can be understood. For example, $\mathrm{YBaCO}_{2} \mathrm{O}_{6-x}$ has a oxygen stoichiometry close to 5 as per literature

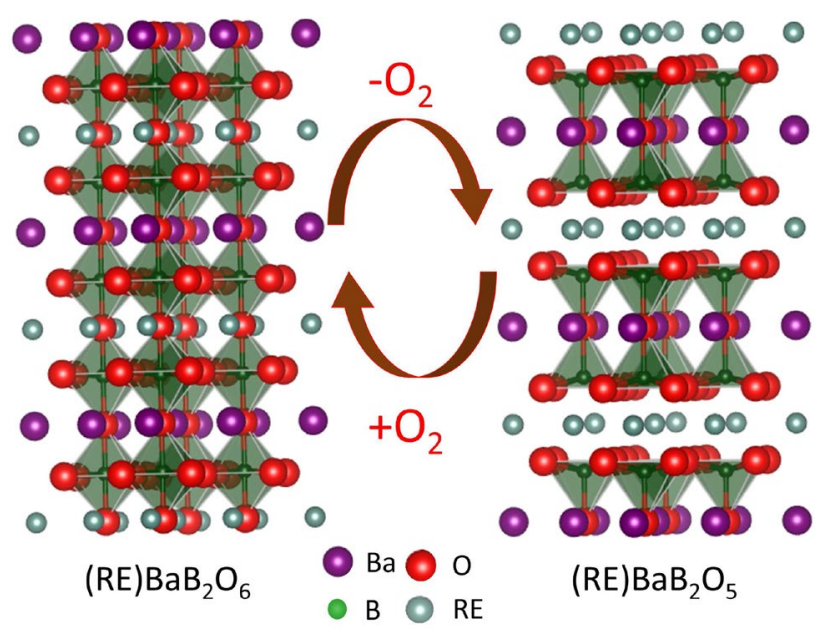

Fig. 2 Reversible structural change in (RE) $\mathrm{BaB}_{2} \mathrm{O}_{6-x}$ 
report [27]. Second is the qualitative comparison of the oxygen intake/release temperature as a function of the rare earth cation radius. A reversible oxygen intake/release was observed for $\mathrm{DyBaCO}_{2} \mathrm{O}_{6-x}$ at $873 \mathrm{~K} \mathrm{[28]} \mathrm{by} \mathrm{switch-}$ ing the atmosphere $\mathrm{O}_{2} / \mathrm{N}_{2}$, while for $\mathrm{YBaCO}_{2} \mathrm{O}_{6-x}$ it is 673 $\mathrm{K}$ by switching the atmosphere $\mathrm{O}_{2} / \mathrm{H}_{2}$ [16]. Third is the easiness in synthesis of the rare earth barium cobaltites, it does not need special reduction treatments or quenching to stabilize the required phase compared to other oxygen storage materials explored $[9,14,17,18]$. Also, the intake/ release observed with a switching of atmosphere $\mathrm{O}_{2} / \mathrm{N}_{2}$ rather than $\mathrm{O}_{2} / \mathrm{H}_{2}$ emphasizes the use of these materials for enriched oxygen stream production.

In this study, relationship between the size of rare earth cation and oxygen intake temperature has been established on the three above mentioned samples synthesized through solid state reaction. Oxygenation/deoxygenation of the samples were characterized using a home-built volumetric setup reported elsewhere [14], thermogravimetric analysis, room temperature $\mathrm{X}$-ray diffraction experiments and iodometric titration. Linear thermal expansion and morphology of the samples before and after the oxygen intake/release were measured to know the changes in the sample, if any, brought about by the redox reactions. The sample DyBaCo $\mathrm{O}_{6-x}$ has been synthesized through solution combustion synthesis to understand the effect of particle size on oxygen intake/release.

\section{Experimental section}

DyBaCo $\mathrm{O}_{6-x}, \mathrm{YBaCo}_{2} \mathrm{O}_{6-x}$ and $\mathrm{Dy}_{0.5} \mathrm{Y}_{0.5} \mathrm{BaCo}_{2} \mathrm{O}_{6-x}$ were synthesized through conventional solid state reaction. Stoichiometric amounts of cobalt oxalate [29], barium carbonate (SD Fine Chemicals, 99\%) and rare earth oxides (Ultrafunction Enterprise Co. LTD, 99.99\%) were mixed together by ball milling in an agate container with agate balls. Ethanol was used as the milling medium with ball to powder ratio of 2:1. Milling was carried out with a speed of $200 \mathrm{rpm}$ for $2 \mathrm{~h}$ in batches of 10 minutes milling and 5 minutes pause time. The fine powder obtained after milling was calcined at $1123 \mathrm{~K}$ for $16 \mathrm{~h}$ followed by a second heat-treatment at $1373 \mathrm{~K}$ for $5 \mathrm{~h}$. The obtained black powder was compacted by applying a pressure of $477 \mathrm{MPa}$ in a steel die and sintered at $1373 \mathrm{~K}$ for $5 \mathrm{~h}$. All the heattreatments were carried out in ambient air atmosphere. The nominal compositions and sample codes for the synthesized samples are given in Table 1.

DyBaCo $\mathrm{O}_{6-x}$ was also synthesized by employing solution combustion synthesis [30] using an aqueous combustion mixture of metal nitrates and glycine (Merk India Pvt. Ltd., 99.7\%) fuel. Stoichiometric amounts of cobalt oxalate, barium carbonate and rare earth oxides were separately
Table 1 Nominal compositions and sample codes of (RE) $\mathrm{BaCO}_{2} \mathrm{O}_{6-x}$ samples

\begin{tabular}{ll}
\hline Nominal composition & Sample code \\
\hline $\mathrm{YBaCO}_{2} \mathrm{O}_{6-x}$ & YBC2-SSS \\
$\mathrm{Dy}_{0.5} \mathrm{Y}_{0.5} \mathrm{BaCO}_{2} \mathrm{O}_{6-x}$ & DYBC2-SSS \\
$\mathrm{DyBaCO}_{2} \mathrm{O}_{6-x}$ & DBC2-SSS \\
\hline
\end{tabular}

Table 2 Synthesis conditions and sample codes of solution combustion synthesized $\mathrm{DyBaCO}_{2} \mathrm{O}_{6-x}$ samples

\begin{tabular}{lll}
\hline Sample code & $\begin{array}{l}\text { Calcination tempera- } \\
\text { ture }(\mathrm{K})\end{array}$ & $\begin{array}{l}\text { Sintering } \\
\text { temperature } \\
(\mathrm{K})\end{array}$ \\
\hline DBC2-1273 & 1273 & 1273 \\
DBC2-1173-1373 & 1173 & 1373 \\
DBC2-1373 & 1373 & 1373 \\
DBC2-1473 & 1473 & 1473 \\
\hline
\end{tabular}

dissolved in nitric acid. This was added to an aqueous solution of glycine. The stoichiometry of metal nitrates and fuel was calculated according to propellant chemistry (Eq. 3) [31]. This was introduced into a pre-heated furnace at 773 $\mathrm{K}$ for combustion reaction to occur. The black powder obtained after combustion was calcined, compacted and sintered in ambient air for 6 hours at different temperatures as given in Table 2 .

$$
\begin{aligned}
& \operatorname{Dy}\left(\mathrm{NO}_{3}\right)_{3}+\mathrm{Ba}\left(\mathrm{NO}_{3}\right)_{2}+2 \mathrm{Co}\left(\mathrm{NO}_{3}\right)_{2}+5 \mathrm{C}_{2} \mathrm{H}_{5} \mathrm{NO}_{2} \\
& +\frac{1}{2} \mathrm{O}_{2} \rightarrow \operatorname{DyBaCO} \mathrm{O}_{6-\mathrm{x}}+10 \mathrm{CO}_{2}+7 \mathrm{~N}_{2}+12.5 \mathrm{H}_{2} \mathrm{O}
\end{aligned}
$$

The phase purity of the samples were analyzed using $\mathrm{X}$-ray diffraction (Cu K $\alpha$, PANalytical X'Pert Pro). For phase identification, the data was collected in the $2 \theta$ range $10-90^{\circ}$ with a step size of $0.02^{\circ}$ for 20 minutes. Rietveld profile refinements were conducted to find out the lattice parameters on the data collected for 1.5 hours with the same step size as above in the $2 \theta$ range $10-110^{\circ}$.

The morphology of the samples were analyzed using a scanning electron microscope (JEOL-IT 300, LaB $_{6}$ source). Average particle size of the synthesized samples were measured manually by the use of ImageJ software [32]. Thermogravimetric analysis was performed to determine the oxygen absorption and release temperatures of the rare earth barium cobaltite samples. About $15-20 \mathrm{mg}$ of the rare earth barium cobaltite sample was heated under oxygen atmosphere in a thermogravimetric balance (Q50, TA instruments) from room temperature to $1173 \mathrm{~K}$ with a heating rate of $10 \mathrm{~K} / \mathrm{min}$.

The oxygen intake/release properties of the samples were measured using a home-built volumetric setup 
reported elsewhere [14]. The temperatures of absorption/ desorption obtained from TGA were used as reference in the intake/release measurements with volumetric setup. In a typical oxygenation experiment, about $1 \mathrm{~g}$ of the sample was pressurized with oxygen/air in the volumetric setup and was heated to the absorption temperature. It was then held isothermal at that temperature for 1 hour and cooled to room temperature in the same atmosphere. The amount of oxygen that can be reversibly incorporated to the sample is calculated from the desorption experiment. A known amount of the oxygenated sample was kept in the evacuated volumetric setup and was heated to the desorption temperature, where the stored oxygen is evolved. Pressure change in the chamber on oxygen evolution was used to calculate the amount of oxygen that can be stored in the sample using ideal gas equation, knowing the volume of the chamber and sample weight. Oxygen intake/release was also characterized by iodometric titration on a known amount of the as synthesized, absorbed and desorbed samples (c.a. $30 \mathrm{mg}$ ) [33].

The linear thermal expansion behavior of the samples before and after oxygen absorption were analyzed using dil-atometry under ambient air atmosphere. Measurements were carried out from room temperature to $1173 \mathrm{~K}$ with a heating rate of $5 \mathrm{~K} / \mathrm{min}$ in a differential dilatometer with alumina reference and measuring system (DIL 802, TA instruments). Sintered pellets of the samples cut into rectangular bars of $10 \mathrm{~mm}$ length and approximately 2 $\mathrm{mm} \times 2 \mathrm{~mm}$ cross section were used for measuring thermal expansion. Similar samples were oxygenated in the volumetric setup and further used for thermal expansion measurements.

\section{Results and discussion}

\section{$3.1(\mathrm{RE}) \mathrm{BaCO}_{2} \mathrm{O}_{6-x}$}

\subsubsection{Structural characterization}

Figure 3 shows the XRD patterns of the solid state synthesized (RE) BaCo $\mathrm{O}_{6-x}$ samples. The samples YBC2-SSS and DYBC2-SSS are phase pure crystallizing with tetragonal symmetry (space group $P 4 / \mathrm{mmm}$ ) while DBC2-SSS crystallizes with orthorhombic symmetry (space group Pmma). A small amount of the tetragonal phase was also observed for DBC2-SSS sample. Few small peaks were observed around $30^{\circ} 2 \theta$ in the XRD pattern of YBC2-SSS samples. This corresponds to superlattice reflections by an oxygen vacancy ordering to form $3 a_{p} \times 3 a_{p} \times 2 a_{p}$ cell where $a_{p}$ is the perovskite lattice parameter $[34,35]$. The lattice parameters and unit cell volumes were calculated

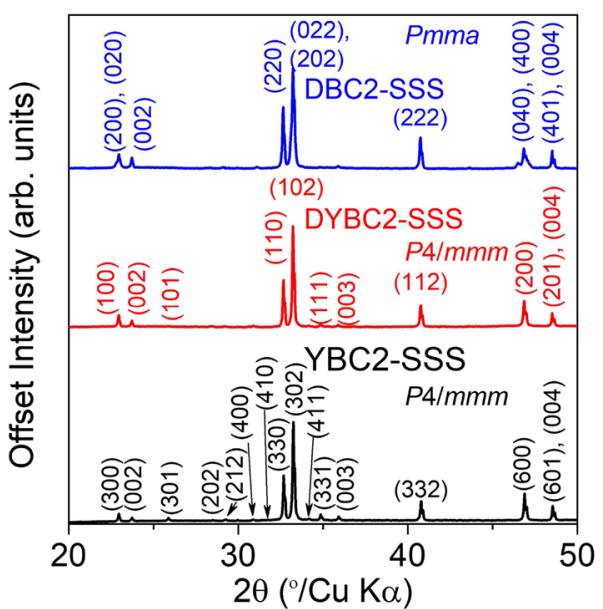

Fig. 3 XRD pattern of the as synthesized (RE) $\mathrm{BaCO}_{2} \mathrm{O}_{6-x}$

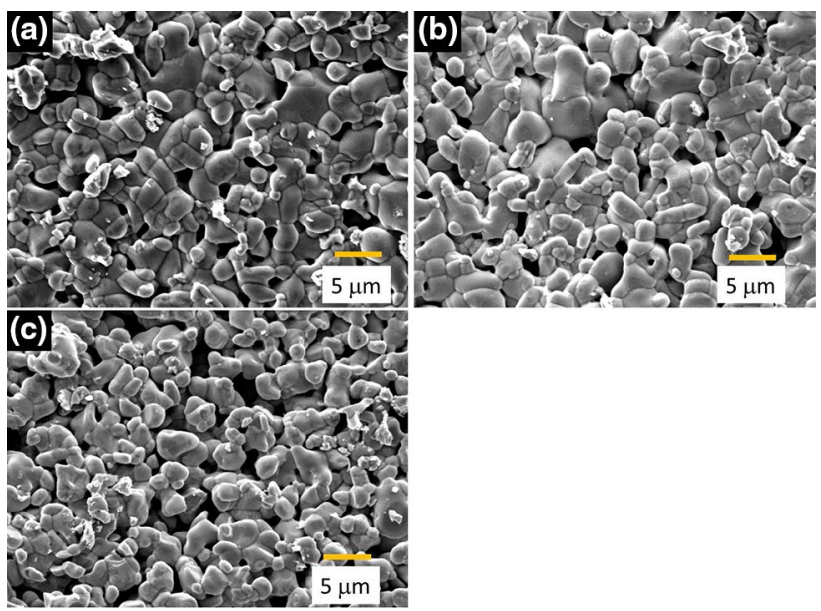

Fig. 4 Scanning electron micrographs of a YBC2-SSS, b DYBC2-SSS and c DBC2-SSS

using Rietveld profile refinement and are tabulated in Table S1. As expected, the normalized unit cell volumes and lattice parameters increased with increase in rare earth cation size. The normalized unit cell volume increases in the order, YBC2-SSS < DYBC2-SSS < DBC2-SSS.

\subsubsection{Morphological characterization}

Scanning electron micrographs of YBC2-SSS, DYBC2-SSS and DBC2-SSS samples are given in Fig. $4 a-c$. All three samples show agglomerated particles of globular shape. The average particle size was found to be similar (2.5-3 $\mu \mathrm{m})$ for all samples as shown in Table 3. 


\subsubsection{Thermogravimetric studies}

Before performing oxygen holding capacity measurements in the home-built setup, the approximate temperature for oxygen intake/release was assessed using TGA. Figure $5 a$, $b$ shows the TGA and derivative curves for YBC2SSS and DBC2-SSS in oxygen atmosphere. A gain/loss in weight is indicated by a dip/peak in the derivative curve (Fig. 5b) respectively. For DBC2-SSS sample, a dip was observed around $518 \mathrm{~K}$ while for YBC2-SSS sample it was $590 \mathrm{~K}$, indicating oxygen intake at these temperatures. For the sample YBC2-SSS, a peak indicating oxygen loss was observed at $656 \mathrm{~K}$. The oxygen loss was observed to be in two steps for DBC2-SSS, at 623 and $673 \mathrm{~K}$. The percentage of weight change on oxygen intake and release were converted to corresponding delta values and were found to be $\approx 0.02$ (intake) and $\approx 0.27$ (release) for both DBC2-SSS and YBC2-SSS samples. This is very low compared to the
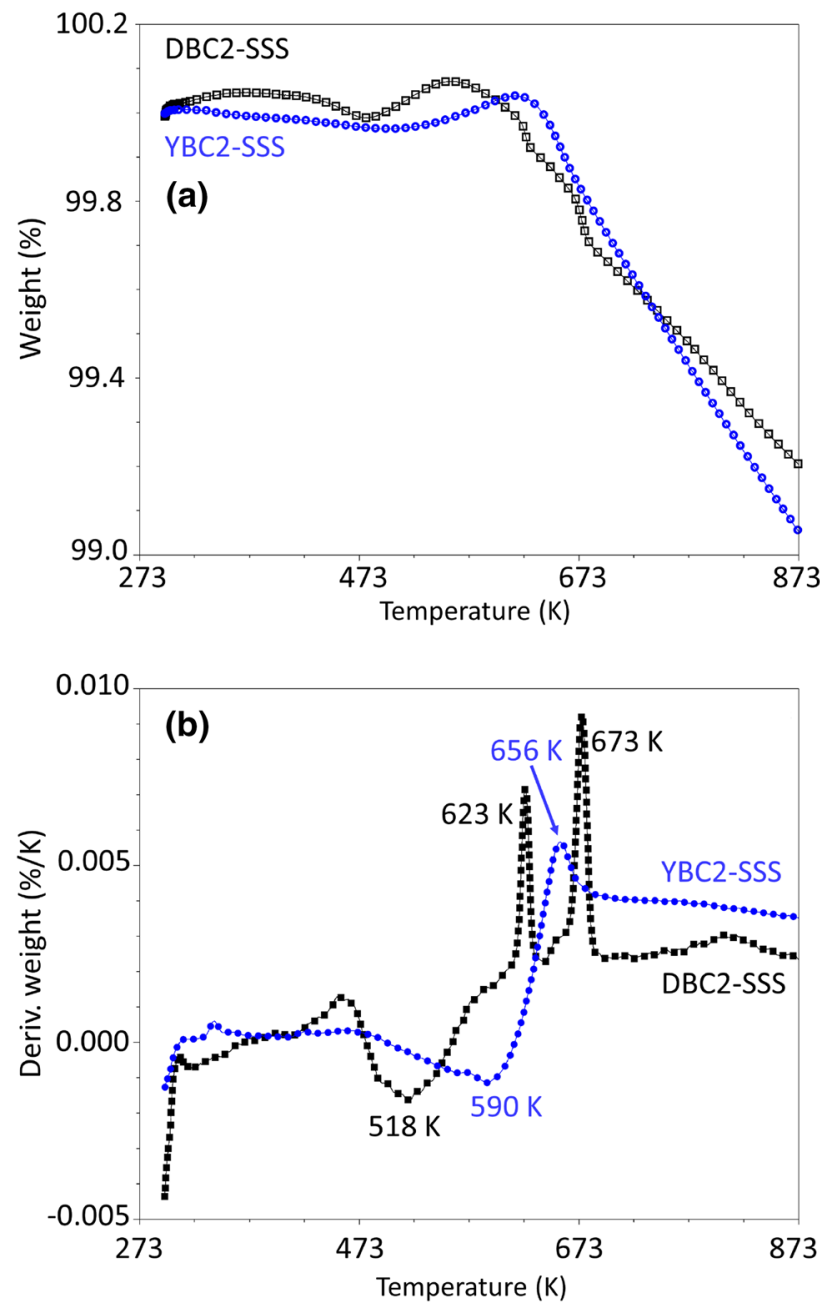

Fig. 5 a TGA curves and $\mathbf{b}$ derivative plots for samples YBC2-SSS and DBC2-SSS expected value of 1 , indicating the necessity of high pressure absorption and low pressure desorption.

Thus, the dynamic TGA measurements were used as an aid to find out the equilibrium oxygen intake/ release temperatures. Maximum intake and release can be obtained by varying the conditions of pressure for absorption and desorption. The absorption temperatures for the three samples were selected as follows, fixing the time and absorption pressure to be 1 hour and 16 bar $\mathrm{O}_{2}$ respectively:

YBC2-SSS: 523-623 K, $25 \mathrm{~K}$ interval

DYBC2-SSS: 523-598 K, 25 K interval

DBC2-SSS: 473-548 K, $25 \mathrm{~K}$ interval

The desorption temperature was selected to be well above the oxygen release temperatures from TGA study, as $723 \mathrm{~K}$.

\subsubsection{Oxygen holding capacity measurements}

Oxygenation of the (RE) $\mathrm{BaCO}_{2} \mathrm{O}_{6-x}$ samples were carried out as explained in Sect. 2 with the parameters derived from TGA study (Sect. 3.1.3). Representative XRD patterns of the absorbed samples are given in Fig. 6a, in comparison with as synthesized YBC2-SSS sample. Few peaks in the XRD pattern of all the absorbed samples for DBC2-SSS show a peak split. Similarly, DYBC2-SSS samples absorbed above $548 \mathrm{~K}$ and YBC2-SSS samples absorbed above 623 $\mathrm{K}$ also show a peak split. These XRD pattern having split peaks can be indexed considering a unit cell based on Pmma space group. This shows a reduction in crystal symmetry with absorption.

The absorbed samples were heated to $723 \mathrm{~K}$ with a heating rate of $7 \mathrm{~K} / \mathrm{min}$ under reduced pressure in the home-built volumetric setup for studying desorption characteristics. It was held isothermal for 1 hour at $723 \mathrm{~K}$ to make sure that desorption was complete. The pressure change due to oxygen evolution was converted to volume of oxygen which can be reversibly incorporated into the material [14]. Representative desorption curves of the absorbed samples are given in Fig. $6 \mathrm{~b}$, c. Figure $6 \mathrm{~b}$ shows the desorption curves for all the three samples absorbed at $523 \mathrm{~K}$, while Fig. $6 \mathrm{c}$ shows the desorption curves of the maximum absorbed samples. It can be seen from Fig. 6b, $c$ that the onset temperature of desorption decreases with increase in rare earth cation size.

The amount of $\mathrm{O}_{2}$ evolved during the desorption study as a function of absorption temperature for all the samples is given in Fig. 7a-c. The reversible oxygen intake $(\delta)$ values calculated from the desorption experiments as well as from iodometric titration are also given in Fig. $7 a-c$. As temperature increases, absorption increases and then decreases as seen from Fig. 7b, c for DYBC2-SSS and DBC2SSS samples. The increase in absorption can be due to 
(a)

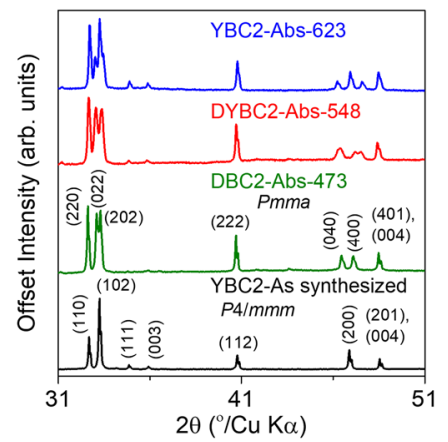

(b)

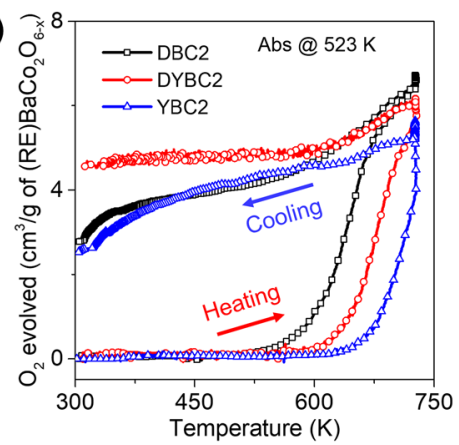

(c)

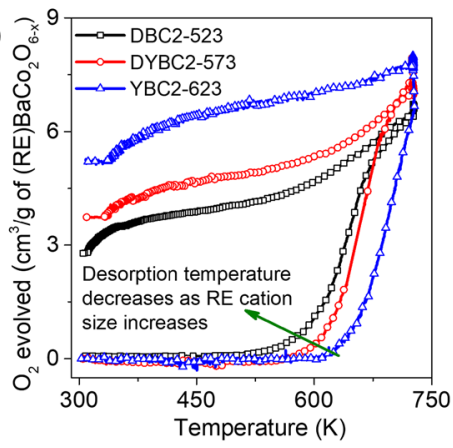

Fig. 6 a XRD patterns of the absorbed (RE) $\mathrm{BaCO}_{2} \mathrm{O}_{6-x}$ samples compared to as synthesized YBC2 sample. Desorption curves of (RE) $\mathrm{BaCO}_{2} \mathrm{O}_{6-x}$ samples (a) absorbed at $523 \mathrm{~K}$ (b) absorbed at respective temperature of maximum absorption

enhancement in ionic mobility as well as chemisorption with increased temperature. The decrease can be attributed to rise in desorption rate which always occurs in equilibrium with chemisorption. In case of YBC2-SSS sample, oxygen intake was found to increase with rise in temperature in the measured temperature range. The maximum absorption temperature varied for samples with different rare earth cations. The sample DBC2-SSS was found to have the lowest absorption temperature, $523 \mathrm{~K}$, while YBC2-SSS was found to have highest absorption temperature, above $648 \mathrm{~K}$. The XRD patterns of the samples after desorption are given in Fig. $\mathrm{S} 1$ and shows that the samples has been converted back to the de-oxygenated phase. To know the selective absorption of oxygen from air, absorption was carried out by pressurizing with 16 bar air ( $20 \%$ $\mathrm{O}_{2}$ and $80 \% \mathrm{~N}_{2}$ ) and heating to the respective maximum
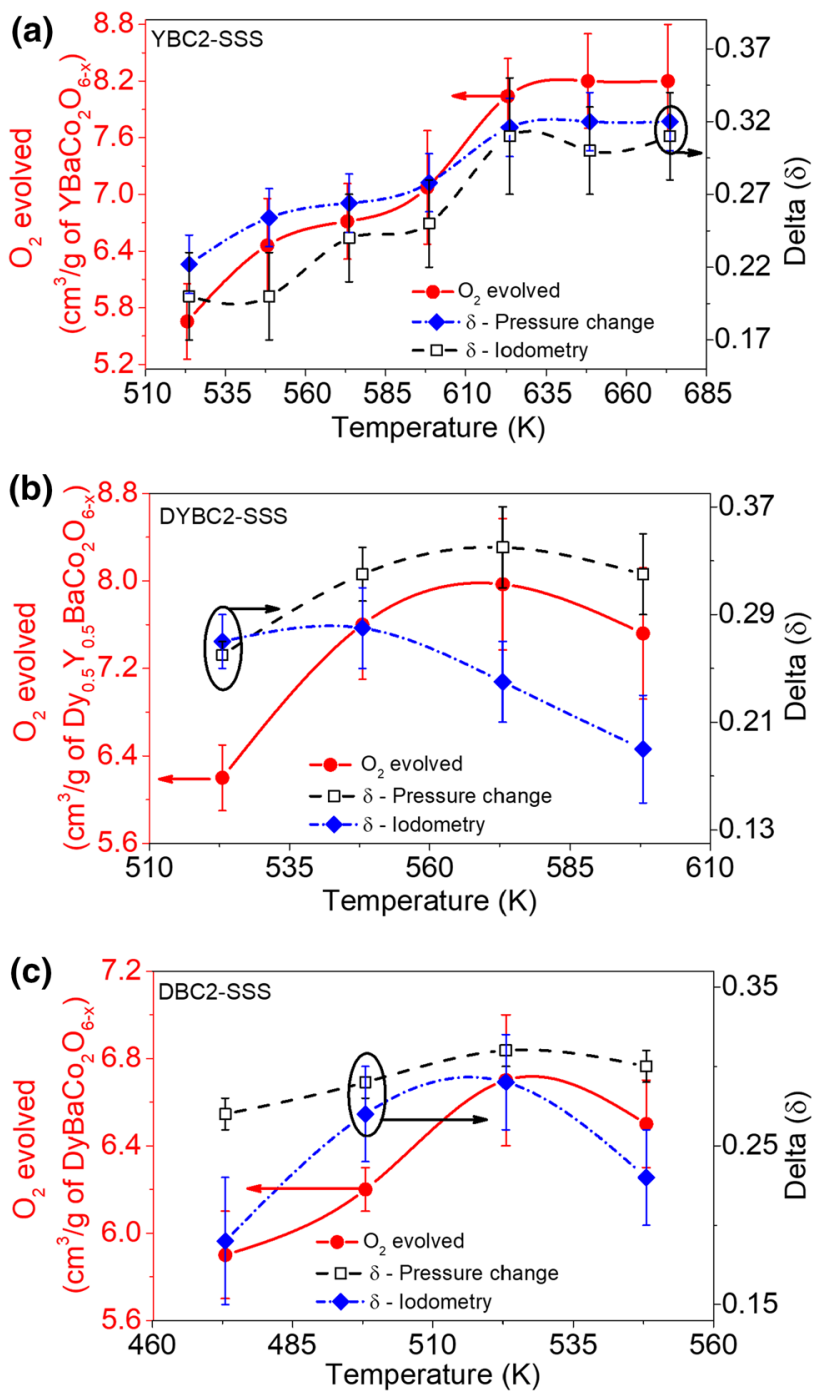

Fig. 7 Comparison of $\mathrm{O}_{2}$ evolved and delta values for $\mathbf{a}$ YBC2-SSS, $\mathbf{b}$ DYBC2-SSS and c DBC2-SSS

absorption temperatures. The desorption curves of these samples are shown in Fig. 8. It can be seen that the sample selectively absorbs oxygen from air and the amount of oxygen absorbed is similar to that absorbed in $\mathrm{O}_{2}$. Oxygen release of DYBC2-SSS sample was found to be slow compared to other two samples (Fig. 8), may be because of the difference in their particle size. DYBC2-SSS has a slightly higher particle size compared to DBC2-SSS and YBC2-SSS samples (Table 3 ).

The change in oxygen absorption temperature for different rare earth barium cobaltites can be attributed to the changes in the critical radii and lattice free volume (Sect. 1). These two geometrical parameters were calculated using the unit cell volume and lattice parameters obtained from the profile refinement and the Shannon's ionic radius value of $\mathrm{Dy}, \mathrm{Y}, \mathrm{Ba}, \mathrm{Co}$ and $\mathrm{O}$ for the respective 


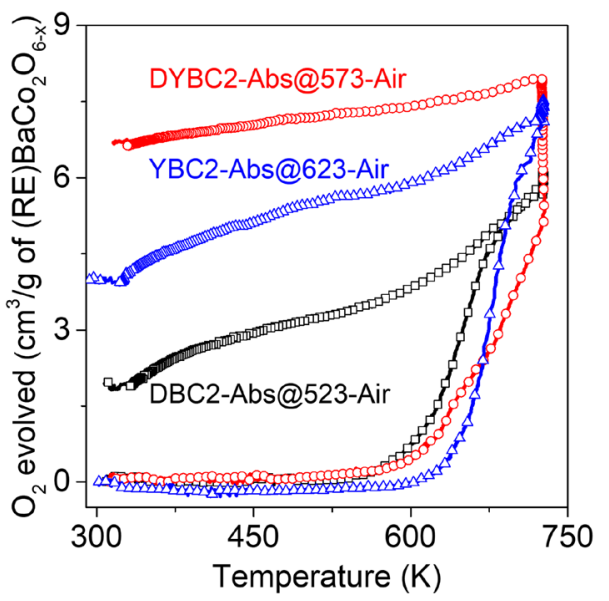

Fig. 8 Desorption curves of samples YBC2-SSS, DYBC2 and DBC2SSS absorbed in air

coordination numbers [36]. Table 3 shows the volume of $\mathrm{O}_{2}$ evolved along with the temperature of maximum absorption and the two geometrical parameters. It can be seen from the Table 3 that as rare earth cation radii increases, critical radius increases, which reduces the absorption temperature. This may be associated with the enhanced oxide ion diffusion due to an increase in the critical radii brought about by the changes in rare earth cation radius. In literature [37, 38], a decrease in the activation energy of oxide ion conduction is attributed to an increase in rare earth cation radius for different cation ordered (RE) $\mathrm{BaCO}_{2} \mathrm{O}_{6-x}$. A corresponding enhancement in ionic diffusion rates are also observed in (RE) $\mathrm{BaCO}_{2} \mathrm{O}_{6-x}$ with rare earth cation of bigger ionic radius [38]. We also observed a reduction in the volume of $\mathrm{O}_{2}$ which can be reversibly incorporated per gram of the sample with an increase in the radius of rare earth cation. The delta values are almost similar in all three cases (Table 3), this decrease might be because of the increase in molecular weight of the material.

\subsubsection{Thermal expansion measurements}

Differences in the thermal expansion behavior of the oxygenated and de-oxygenated material is an important parameter to be considered for long time usage of the material for oxygen separation. Linear thermal expansion of as synthesized and absorbed (RE) $\mathrm{BaCO}_{2} \mathrm{O}_{6-x}$ samples with temperature up to $1200 \mathrm{~K}$ is given in Fig. 9a, b. The expansion behavior is linear with temperature indicating the absence of any phase transition in the studied temperature range. No drastic difference in the expansion was observed due to oxygen absorption/evolution. A slight change in slope of the linear expansion curve was observed above $473 \mathrm{~K}$ and $573 \mathrm{~K}$ for DBC2 and YBC2 samples, respectively. The thermal expansion coefficients (TEC) of all three as synthesized as well as the absorbed samples as a function of temperature are also given in Fig. 9a, b. The samples after absorption show a slightly higher thermal expansion coefficient compared to the as synthesized samples (Table 4). The expansion behavior of oxide materials is considered to have two parts-increased molecular vibrations which are anharmonic and chemical expansion due to thermal reduction. The difference in TEC of as synthesized and absorbed samples may be because of the chemical expansion brought about by oxygen evolution.

\subsubsection{Morphology after desorption}

Morphology of the sample after oxygen absorption/desorption study was assessed to find the changes if any, occurred during the redox reactions. The morphology was observed to be same after the oxygen intake/release studies [Fig. S2 $(\mathrm{a}-\mathrm{c})$ ] since oxygen incorporation does not involve a restructuring of the lattice. Oxygen simply intercalates/de-intercalates into the firm metal sub-lattice.

In summary, the oxygen intake temperatures of (RE) $\mathrm{BaCO}_{2} \mathrm{O}_{6-x}$ samples synthesized through solid state reaction were found to vary depending on the rare earth cation size. $\mathrm{DyBaCO}_{2} \mathrm{O}_{6-x}$ was found to possess the lowest absorption temperature, $523 \mathrm{~K}$ and thus can be considered to be an ideal candidate for oxygen enrichment and separation using the low temperature waste heat. Improvement in oxygen holding capacity of $\mathrm{DyBaCO} \mathrm{O}_{6-x}$ was attempted by varying synthesis method, which is discussed in the next section.

Table 3 Comparison of oxygen evolved, delta, lattice free volume, critical radii and average particle size for $(\mathrm{RE}) \mathrm{BaCO}_{2} \mathrm{O}_{6-x} \mathrm{samples}$

\begin{tabular}{|c|c|c|c|c|c|c|c|}
\hline Sample code & $\begin{array}{l}\text { Temperature of } \\
\text { maximum absorp- } \\
\text { tion }(\mathrm{K})\end{array}$ & $\begin{array}{l}\text { Molecular weight of } \\
(\mathrm{RE}) \mathrm{BaCO}_{2} \mathrm{O}_{6}(\mathrm{~g} / \mathrm{mol})\end{array}$ & $\begin{array}{l}\mathrm{O}_{2} \text { evolved } \\
\left(\mathrm{cm}^{3} / \mathrm{g}\right) \text { and } \\
\text { delta }(\delta)\end{array}$ & $\begin{array}{l}\text { Normalized } \\
\text { cell volume } \\
\left(\AA^{3}\right)\end{array}$ & $\begin{array}{l}\text { Lattice free } \\
\text { volume }\left(\AA^{3}\right)\end{array}$ & Critical radii $(\AA ̊)$ & $\begin{array}{l}\text { Average } \\
\text { particle size } \\
(\mu \mathrm{m})\end{array}$ \\
\hline YBC2-SSS & 673 & 440.099 & $8.2 \pm 0.6$ and 0.32 & $112.544(14)$ & 11.593 & 0.922 & $2.6 \pm 1.0$ \\
\hline DYBC2-SSS & 573 & 476.896 & $8.0 \pm 0.6$ and 0.34 & $112.720(15)$ & 11.376 & 0.924 & $3.0 \pm 1.0$ \\
\hline DBC2-SSS & 523 & 513.693 & $6.7 \pm 0.3$ and 0.32 & $112.968(15)$ & 11.933 & 0.934 & $2.5 \pm 0.8$ \\
\hline
\end{tabular}


(a)

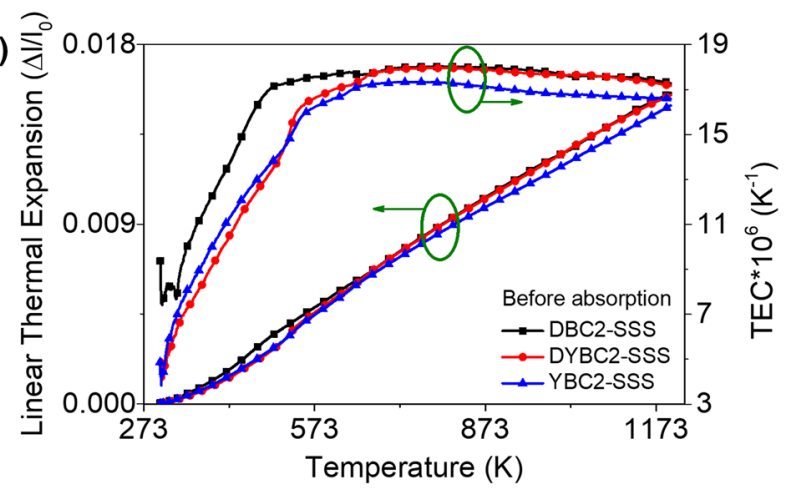

(b)

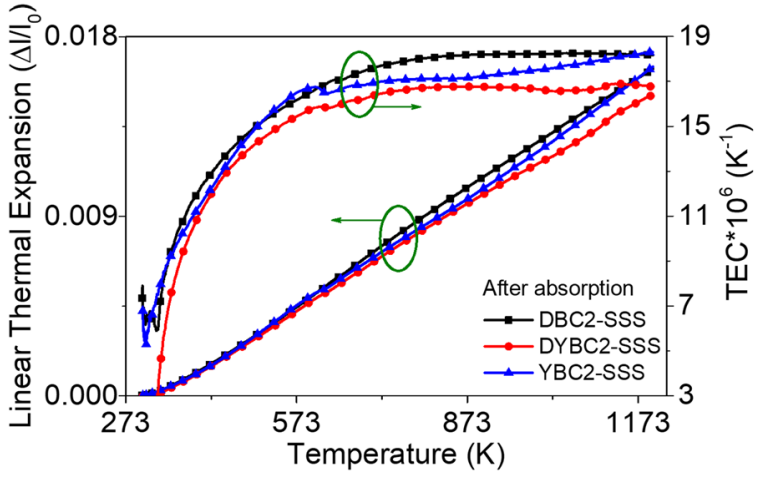

Fig. 9 Linear thermal expansion of the a as synthesized YBC2-SSS DYBC2-SSS and DBC2-SSS samples and $\mathbf{b}$ absorbed samples. Variation of TEC with temperature for the samples are shown in the right hand side axis

Table 4 Thermal expansion coefficients of as synthesized and absorbed (RE) $\mathrm{BaCO}_{2} \mathrm{O}_{6-x}$ samples above $700 \mathrm{~K}$

\begin{tabular}{lll}
\hline Sample Code & \multicolumn{2}{l}{ TEC $* 10^{6} \mathrm{~K}^{-1}(\mathrm{~T}>700 \mathrm{~K})$} \\
\cline { 2 - 3 } & Before (BA) & After (AA) \\
\hline YBC2-SSS & 15.8 & 19.3 \\
DYBC2-SSS & 16.8 & 16.7 \\
DBC2-SSS & 16.8 & 18.6 \\
\hline
\end{tabular}

\section{2 $\mathrm{DyBaCO}_{2} \mathrm{O}_{6-x}$ by solution combustion synthesis}

\subsubsection{Structural and morphological characterizations}

XRD patterns of the solution combustion synthesized DyBaCo $\mathrm{O}_{6-x}$ samples are shown in Fig. $\mathrm{S} 3(\mathrm{a}-\mathrm{b})$. The samples sintered at higher temperatures (1373 K and $1473 \mathrm{~K}$ ) are single phase double perovskite and the peaks in XRD pattern can be indexed based on Pmma space group. Even though the other two samples can be indexed based on the same space group, splitting of few peaks were observed. Careful observation of the miller indices [Fig. S3 (a-b)] and lattice parameters (Table 5) indicates that the symmetry has changed from a pseudo tetragonal to orthorhombic. Rietveld profile refinements were carried out for the samples and the lattice parameters are tabulated in Table 5. From iodometric titration (Table 5), it is evident that the samples sintered at lower temperatures are oxygen rich compared to the sample sintered at higher temperatures.

The scanning electron micrographs of the solution combustion synthesized $\mathrm{DyBaCO}_{2} \mathrm{O}_{6-x}$ samples are given in Fig. 10a-d. It can be seen from the micrographs that as sintering temperature increases, particle size of the sample increases. The average particle size of the samples was calculated as given in Table 6.

\subsubsection{Oxygen holding capacity measurements}

Oxygen holding capacities of the samples were measured using the home built volumetric setup (Sect. 2). Oxygen loading of the samples was carried out by pressurizing it with 16 bar $\mathrm{O}_{2}$ and heating to $523 \mathrm{~K}$. It was held isothermal at $523 \mathrm{~K}$ for 1 hour and cooled down to room temperature in the same atmosphere. The samples after absorption were characterized with XRD to assess oxygen absorption. The XRD pattern of the samples after absorption is given in Fig. S3(c). The samples sintered at a temperature up to $1373 \mathrm{~K}$ show peak splitting while the one sintered at $1473 \mathrm{~K}$ does not. Figure 11 shows the desorption curves of the absorbed samples. It can be seen that as sintering temperature increases, oxygen holding capacity decreases (Fig. 11, Table 6). This can be attributed to the increase in particle size (Table 6) or decrease in surface area with increased sintering temperature. The XRD pattern of the samples after desorption matches that of the as synthesized samples, showing reversibility [Fig. S3(d)]. As the samples DBC2-1273 and DBC2-1173-1373 already had higher oxygen content, the reversible absorption/
Table 5 Lattice parameters, unit cell volumes and oxygen content (iodometry) of DyBaCo $\mathrm{O}_{6-x}$ samples obtained from Rietveld profile refinement

\begin{tabular}{|c|c|c|c|c|c|c|}
\hline \multirow[t]{2}{*}{ Sample code } & \multicolumn{3}{|c|}{ Lattice parameters $(\AA)$} & \multirow{2}{*}{$\begin{array}{l}\text { Unit cell volume } \\
\left(\AA^{3}\right)\end{array}$} & \multirow{2}{*}{$\begin{array}{l}\text { Goodness } \\
\text { of fit }\end{array}$} & \multirow{2}{*}{$\begin{array}{l}\text { Oxygen content } \\
\text { (iodometry) }\end{array}$} \\
\hline & a & $b$ & c & & & \\
\hline DBC2-1273 & 7.724(7) & $7.802(5)$ & $7.505(6)$ & $452.271(18)$ & 1.96 & $6.03 \pm 0.02$ \\
\hline DBC2-1173-1373 & $7.726(2)$ & $7.800(2)$ & $7.506(4)$ & $452.332(8)$ & 2.20 & $5.99 \pm 0.02$ \\
\hline DBC2-1373 & 7.753(4) & $7.762(2)$ & $7.505(7)$ & $451.641(13)$ & 2.11 & $5.97 \pm 0.02$ \\
\hline DBC2-1473 & $7.757(4)$ & $7.760(3)$ & 7.505(8) & $451.758(15)$ & 2.29 & $5.70 \pm 0.02$ \\
\hline
\end{tabular}



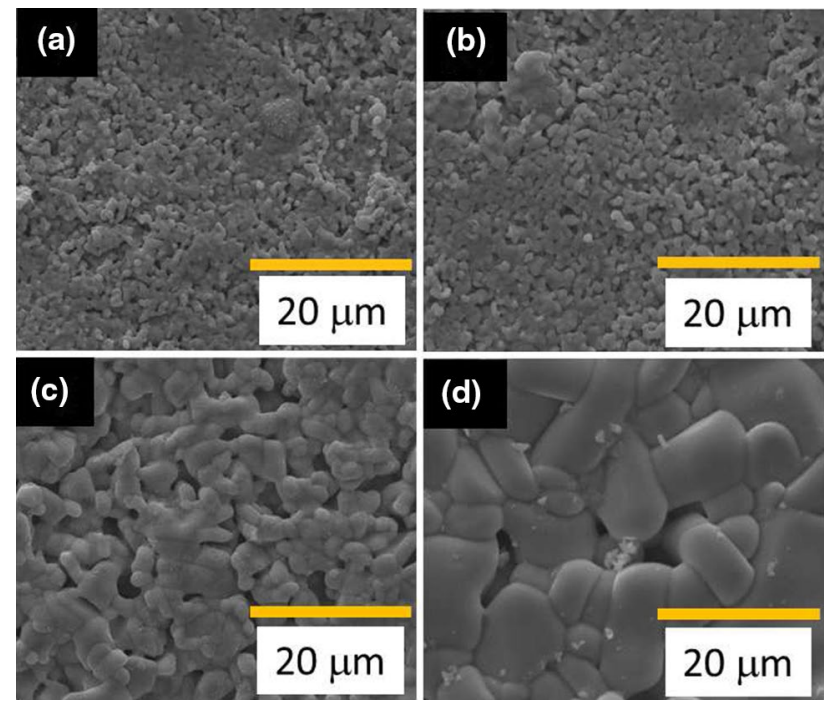

Fig. 10 Scanning electron micrographs of a DBC2-1173-1373, b DBC2-1273, c DBC2-1373 and d DBC2-1473

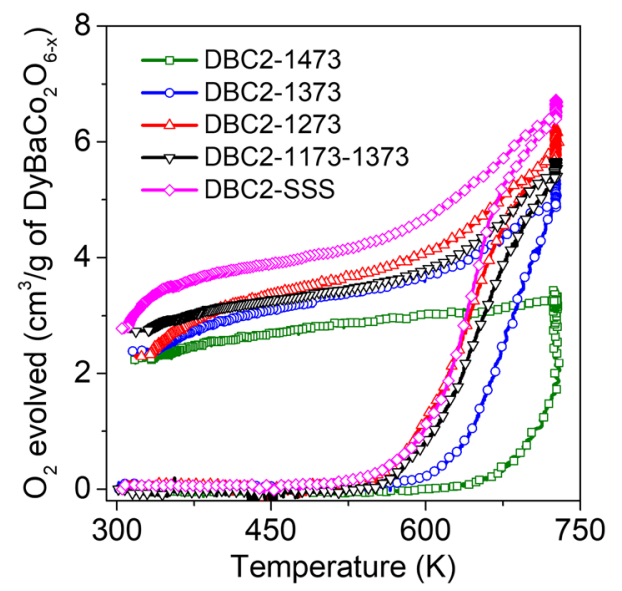

Fig. 11 Desorption curves of the absorbed solution combustion synthesized $\mathrm{DyBaCO}_{2} \mathrm{O}_{6-x}$ samples

Table 6 Comparison of oxygen holding capacities of solution combustion synthesized $\mathrm{DyBaCO}_{2} \mathrm{O}_{6-x}$ samples sintered at different temperatures

\begin{tabular}{llc}
\hline Sample code & $\mathrm{O}_{2}$ evolved $\left(\mathrm{cm}^{3} / \mathrm{g}\right)$ & $\begin{array}{l}\text { Average } \\
\text { particle size } \\
(\mu \mathrm{m})\end{array}$ \\
\hline DBC2-SSS & 6.73 & $2.5 \pm 0.8$ \\
DBC2-1273 & 6.27 & $1.3 \pm 0.5$ \\
DBC2-1273-2nd run & 6.49 & $1.3 \pm 0.5$ \\
DBC2-1173-1373 & 5.64 & $0.9 \pm 0.2$ \\
DBC2-1373 & 5.35 & $4 \pm 1$ \\
DBC2-1473 & 3.45 & $15 \pm 6$ \\
\hline
\end{tabular}

desorption was confirmed by a second run, the result of which matches with that of first run (Table 6).

\section{Conclusions}

(RE) $\mathrm{BaCO}_{2} \mathrm{O}_{6-x}(\mathrm{RE}=\mathrm{Y}$, Dy) have been successfully demonstrated for low temperature oxygen enrichment applications. Oxygen holding capacity per gram of the material decreases with increase in size of the rare earth, mainly because of the increase in molecular weight of the sample. The temperatures of oxygen intake and release reduces with increase in rare earth cation size, due to an enlargement in the critical radius of the saddle point through which oxide ion migration occurs. The effect of synthesis method and there by particle size of $\mathrm{DyBaCO}_{2} \mathrm{O}_{6-x}$ on oxygen holding capacity was also analyzed. The amount of oxygen that can be reversibly incorporated into the lattice of DyBaCo $\mathrm{O}_{6-x}$ reduces with increase in particle size. Hence, rare earth based barium cobaltites can be considered to be an ideal candidate for oxygen enrichment and separation using low temperature waste heat.

Acknowledgements Supercomputer Education and Research Centre (SERC), IISc is acknowledged for providing access for LabVIEW 7 program. A.M.N. acknowledges Council of Scientific and Industrial Research (CSIR), Govt. of India for the financial support in the form of Junior and Senior Research Fellowship. Authors acknowledge Advanced Facility for Microscopy and Microanalysis, IISc for providing SEM facility. The funding received from FIST for XRD, TGA and dilatometry facilities are acknowledged. Authors would like to thank Prof. A. Ramanan from Department of Chemistry, IIT Delhi for his suggestions on this work.

\section{Compliance with ethical standards}

Conflict of interest The authors declare that they have no conflict of interest.

\section{References}

1. Montini T, Melchionna M, Monai M, Fornasiero P (2016) Fundamentals and catalytic applications of $\mathrm{CeO}_{2}$-based materials. Chem Rev 116(10):5987

2. $\mathrm{Kim} \mathrm{JH}$, Manthiram A (2008) $\mathrm{LnBaCO}_{2} \mathrm{O}_{5+\delta}$ oxides as cathodes for intermediate-temperature solid oxide fuel cells. J Electrochem Soc 155(4):B385

3. Fergus JW (2007) Perovskite oxides for semiconductor-based gas sensors. Sens Actuators B Chem 123(2):1169

4. Badwal SP, Ciacchi FT (2001) Ceramic membrane technologies for oxygen separation. Adv Mater 13(12-13):993

5. Demizu A, Beppu K, Hosokawa S, Kato K, Asakura H, Teramura K, Tanaka $T$ (2017) Oxygen storage property and chemical stability of $\mathrm{SrFe}_{1-x} \mathrm{Ti}_{x} \mathrm{O}_{3-\delta}$ with robust perovskite structure. J Phys Chem C 121(35):19358

6. Karppinen M, Yamauchi H, Otani S, Fujita T, Motohashi T, Huang YH, Valkeapää M, Fjellvåg H (2006) Oxygen nonstoichiometry in 
$\mathrm{YBaCo}_{4} \mathrm{O}_{7+\delta}$ : large low-temperature oxygen absorption/desorption capability. Chem Mater 18(2):490

7. Lin YS, MacLean DL, Zeng Y (May 9, 2000) High temperature adsorption process, US Patent

8. Li P, Chen X, Li Y, Schwank JW (2019) A review on oxygen storage capacity of $\mathrm{CeO}_{2}$-based materials: influence factors, measurement techniques, and applications in reactions related to catalytic automotive emissions control. Catal Today 327:90

9. Kadota S, Karppinen M, Motohashi T, Yamauchi H (2008) R-site substitution effect on the oxygen-storage capability of $\mathrm{RBaCO}_{4} \mathrm{O}_{7+\delta}$. Chem Mater 20(20):6378

10. Hervieu M, Guesdon A, Bourgeois J, Elkaim E, Poienar M, Damay F, Rouquette J, Maignan A (2014) Oxygen storage capacity and structural flexibility of LuFe $\mathrm{O}_{4+x}(0 \leq x \leq 0.5)$. Nat Mater 13(1):74

11. Wu HC, Lin Y (2017) Effects of oxygen vacancy order-disorder phase transition on air separation by perovskite sorbents. Ind Eng Chem Res 56(20):6057

12. Beppu K, Hosokawa S, Shibano T, Demizu A, Kato K, Wada K, Asakura H, Teramura K, Tanaka T (2017) Enhanced oxygenrelease/storage properties of $\mathrm{Pd}$-loaded $\mathrm{Sr}_{3} \mathrm{Fe}_{2} \mathrm{O}_{7-\delta}$. Phys Chem Chem Phys 19(21):14107

13. Nicoud $S$, Huvé $M$, Hernandez $O$, Pautrat $A$, Duttine $M$, Wattiaux A, Colin C, Kabbour H, Mentré O (2017) Comprehensive study of oxygen storage in $\mathrm{YbFe}_{2} \mathrm{O}_{4+x}(\mathrm{x} \leq 0.5)$ : unprecedented coexistence of FeOn polyhedra in one single phase. J Am Chem Soc 139(47): 17031

14. Narayanan AM, Parasuraman R, Umarji AM (2018) Stabilization of Brownmillerite type $\mathrm{SrCoO}_{2.5}$ by a cost-effective quenching method for oxygen scavenging applications. Ind Eng Chem Res 57(43):14749

15. Narayanan AM, Umarji AM (2019) Optimization of absorption/ desorption parameters of brownmillerite $\mathrm{SrCoO}_{2.5}$ for oxygen storage. J Alloy Compd 803:102

16. Lekse JW, Natesakhawat S, Alfonso D, Matranga C (2014) An experimental and computational investigation of the oxygen storage properties of $\mathrm{BaLnFe}_{2} \mathrm{O}_{5+\delta}$ and $\mathrm{BaLnCo}_{2} \mathrm{O}_{5+\delta}(\mathrm{Ln}=\mathrm{La}$, Y) perovskites. J Mater Chem A 2:2397

17. Motohashi T, Ueda T, Masubuchi Y, Takiguchi M, Setoyama T, Oshima K, Kikkawa S (2010) Remarkable oxygen intake-release capability of $\mathrm{BaYMn}_{2} \mathrm{O}_{5+\delta}$ : applications to oxygen storage technologies. Chem Mater 22:3192

18. Motohashi T, Hirano Y, Masubuchi Y, Oshima K, Setoyama T, Kikkawa S (2013) Oxygen storage capability of brownmillerite-type $\mathrm{Ca}_{2} \mathrm{AlMnO}_{5+\delta}$ and its application to oxygen enrichment. Chem Mater 25(3):372

19. Kannika Jeamjumnunja WG, Makarenko T, Jacobson AJ (2015) A determination of the oxygen non-stoichiometry of the oxygen storage material $\mathrm{YBaMn}_{2} \mathrm{O}_{5+\delta}$. J Solid State Chem 230:397

20. Klimkowicz A, Świerczek K, Takasaki A, Molenda J, Dabrowski $B$ (2015) Crystal structure and oxygen storage properties of $\mathrm{BaLnMn}_{2} \mathrm{O}_{5+\delta}(\mathrm{Ln}: \mathrm{Pr}, \mathrm{Nd}, \mathrm{Sm}, \mathrm{Gd}, \mathrm{Dy}, \mathrm{Er}$ and $\mathrm{Y}$ ) oxides. Mater Res Bull 65:116

21. Geffroy PM, Blond E, Richet N, Chartier T (2017) Understanding and identifying the oxygen transport mechanisms through a mixed-conductor membrane. Chem Eng Sci 162:245

22. Cook RL, Sammells AF (1991) On the systematic selection of perovskite solid electrolytes for intermediate temperature fuel cells. Solid State Ion 45(3-4):311
23. Lavrov AN, Kameneva MY, Kozeeva LP, Zhdanov KR (2017) Charge-lattice interplay in layered cobaltates $\mathrm{RBaCO}_{2} \mathrm{O}_{5+x}$. J Magn Magn Mater 440:108

24. Rautama EL, Karppinen M (2010) R-site varied series of $\mathrm{RBaCO}_{2} \mathrm{O}_{5.5}\left(\mathrm{R}_{2} \mathrm{Ba}_{2} \mathrm{Co}_{4} \mathrm{O}_{11}\right)$ compounds with precisely controlled oxygen content. J Solid State Chem 183:1102

25. Kim JH, Mogni L, Prado F, Caneiro A, Alonso JA, Manthiram A (2009) High temperature crystal chemistry and oxygen permeation properties of the mixed ionic-electronic conductors $\mathrm{LnBaCO}_{2} \mathrm{O}_{5+\delta}(\mathrm{Ln}=$ lanthanide). J Electrochem Soc 156(12):B1376

26. Zhang K, Ge L, Ran R, Shao Z, Liu S (2008) Synthesis, characterization and evaluation of cation-ordered $\mathrm{LnBaCO}_{2} \mathrm{O}_{5+\delta}$ as materials of oxygen permeation membranes and cathodes of SOFCs. Acta Mater 56(17):4876

27. Barbey L, Nguyen N, Caignaert V, Studer F, Raveau B (1994) Spin state and variation of the spin orientation of $\mathrm{Co}$ (III) in the 112type phase $\mathrm{YBaCo}_{2-x} \mathrm{Cu}_{x} \mathrm{O}_{5}$. J Solid State Chem 112(1):148

28. Behera $S$ (2016) Thermoelectrics and oxygen sensing studies of selected perovskite oxides. Ph.D. thesis, Indian Institute of Science Bangalore-560012, India

29. Wisgerhof E, Geus JW (1984) Morphology and X-ray diffraction pattern of dihydrates of cobalt (II) oxalate. Mater Res Bull 19(12):1591

30. Patil K, Hegde MS, Rattan T, Aruna ST (2008) Chemistry of nanocrystalline oxide materials: combustion synthesis, properties and applications. World Scientific, Singapore

31. Jain S, Adiga K, Verneker VP (1981) A new approach to thermochemical calculations of condensed fuel-oxidizer mixtures. Combust Flame 40:71

32. Schneider CA, Rasband WS, Eliceiri KW (2012) NIH Image to ImageJ: 25 years of image analysis. Nat Methods 9(7):671

33. Karppinen M, Matvejeff M, Salomäki K, Yamauchi H (2002) Oxygen content analysis of functional perovskite-derived cobalt oxides. J Mater Chem 12(6):1761

34. Zhou W, Lin CT, Liang WY (1993) Synthesis and structural studies of the perovskite-related compound $\mathrm{YBaCO}_{2} \mathrm{O}_{5+x}$. Adv Mater 5(10):735

35. Akahoshi D, Ueda Y (2001) Oxygen nonstoichiometry, structures, and physical properties of $\mathrm{YBaCO}_{2} \mathrm{O}_{5+x}(0.00 \leq \mathrm{x} \leq 0.52)$. J Solid State Chem 156(2):355

36. Shannon RD (1976) Revised effective ionic radii and systematic studies of interatomic distances in halides and chalcogenides. Acta Crystallogr Sect A Cryst Phys Diffr Theor Gen Crystallogr 32(5):751

37. Hermet J, Dupé B, Dezanneau G (2012) Simulations of $\mathrm{REBaCO} \mathrm{O}_{5.5}(\mathrm{RE}=\mathrm{Gd}, \mathrm{La}, \mathrm{Y})$ cathode materials through energy minimisation and molecular dynamics. Solid State lon 216:50

38. Tarancón A, Burriel M, Santiso J, Skinner SJ, Kilner JA (2010) Advances in layered oxide cathodes for intermediate temperature solid oxide fuel cells. J Mater Chem 20(19):3799

Publisher's Note Springer Nature remains neutral with regard to jurisdictional claims in published maps and institutional affiliations. 